\title{
Optimization of Thermal Management and Power Density of Small-Scale Wind Turbine Applications using SiC-MOSFETS
}

\author{
Abdallah Hussein, and Alberto Castellazzi \\ The University of Nottingham \\ Power Electronics, Machines and Control (PEMC) Group \\ Nottingham, UK \\ E-mail:eexash@nottingham.ac.uk
}

\begin{abstract}
This paper presents an optimized design of $12 \mathrm{~kW}$ 2L-FB inverter for small-scale wind turbine, taking into account some specific behavioral features of $\mathrm{SiC}$ power MOSFETs. Power converters used in renewable energy conversion have to deal with intermittent and variable power availability from the source, which implies that they actually work at their maximum rated power for only a small fraction of their operational time. Still, traditional thermal management design of power modules has to refer to maximum load conditions. SiC-MOSFETs exhibit a very stable performance over a broad temperature range [1-3]; this feature enables to design the cooling device for nominal operational conditions, typically corresponding to a much lower than maximum power rating. When this capability is added to the decrease in the size of passive filter elements, which can be gained by the higher switching frequency capability of $\mathrm{SiC}$ MOSFETs, the result is a significant increase of the converter powe, density.
\end{abstract}

Keywords-Small-scale wind turbine; Wind speed distribution; Thermal management; SiC-MOSFETs; Two-level converters.

\section{INTRODUCTION}

The development trends of power electronic converters is characterized by the requirements for higher efficiency, lower volume, lower weight, lower costs, higher reliability and quicker system dynamic response. The commercially available $\mathrm{SiC}$ power MOSFETs have the potential to deliver these advantages over a wide range of industrial applications such as PV inverters, solid state transformers, speed drives, and wind turbines. A lot of studies have been done in the application of $\mathrm{SiC}$ devices. [2] presented the stable performance of $\mathrm{SiC}$ Power MOSFETs in PV inverters against switching frequency and heatsink temperature. [4] demonstrated the impact of SiC technology in energy storage integrated solid state transformer, higher power cell efficiency and lower battery losses are achieved at high switching frequency. [5] stated that $\mathrm{SiC}$ converters could improve the control performance of the motor high speed drive system by decreasing the voltage error due to the dead time is reduced. However, few work has been done on the impact of SiC technology in small-scale wind energy. In [6], designed qZS-derived push-pull DC/DC converter in the boost stage of small-scale wind conversion system based on SiC MOSFETs, higher efficiency at high switching frequency is achieved. Our recent work, [7], reported the improvements that could be brought by $\mathrm{SiC}$ MOSFETs in small-Scale wind energy conversion system, the 2L-FB grid inverter presented higher efficiency especially at partial loads in the area of high wind speed distribution. This ensures a good utilization of wind energy resources and a low operating costs. Furthermore, low losses and stable operation of $\mathrm{SiC}$ MOSFETs over a wide range of temperatures allow to increase the converter power density and lead to more compact design. A low converter volume and weight gives an opportunity for simple converter system deployments in terms of installation, handling and maintenance for stationary systems, and particularly important for mobile applications.

The aim of this work is to decrease the heatsink volume and weight and, thus, increase the converter power density by optimize the thermal management design of the inverter heatsink in small-scale wind turbine using SiC MOSFETs. The Heatsink has the main contribution to the total converter volume, this paper is focusing on the thermal management of the cooling system taken into account a very stable performance of SiC-MOSFETs over a wide temperature range. The idea is based on designing the heatsink in the area in which wind turbines spend most of their operational time for nominal operational conditions, typically corresponding to a much lower than maximum power rating. At the maximum wind turbine output power, the power MOSFETs junction temperature increases accordingly for a given heatsink, the heatsink temperature also rises in order to have the heat transfer more effective. This resulting in a smaller heat sink. However, insignificant decrease in efficiency, energy production and reliability are reported.

This paper is organized as follows: description of wind turbine system and modeling is presented in section II; temperature $\mathrm{SiC}$ devices characteristics are modeled in section III; the thermal modeling of a converter system is analyzed in section IV; the heatsink design and volume is demonstrated in section $\mathrm{V}$; the reliability calculation is analyzed in section VI; the thermal management optimization and the resulting thermal management, efficiency, power density and reliability is presented in Section VII and, finally, the conclusion and future work. 


\section{WIND TUURBINE SYSTEM AND MODELING}

\section{A. Small-Scale Wind Turbine Conversion System}

For small-scale wind conversion system in the power ranges up to hundred $\mathrm{kW}$, it is a trend to use a PMSG in industry applications especially for a directly driven wind turbine with benefits of size and weight reduction. As there is no reactive power needed, the conversion system is a simple 3-phase diode rectifier with dc-dc boost converter connected to 2-level full bridge PWM inverter as shown in Fig. $1[8,9]$.

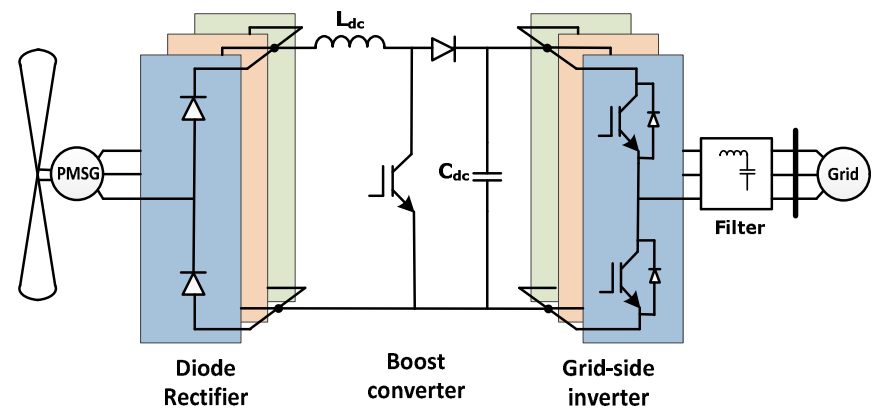

Fig. 1. Small scale wind turbine power conversion system.

\section{B. Simplified Model of Wind Turbine under MPPT}

The focus is on the inverter stage in this work, so that, the wind turbine model under the maximum power point tracking and part of the conversion system (rectifier and boost stages) is simplified by a current source connected in parallel with the DC link capacitor of the grid-side inverter as shown in Fig. 2.

The input signal of the current source is:

$$
I_{w}=P_{w, o p t} / V_{d c} .
$$

Where, $P_{w, \text { opt }}$ is the optimal wind power and $V_{d c}$ is the DC link voltage of the converter.

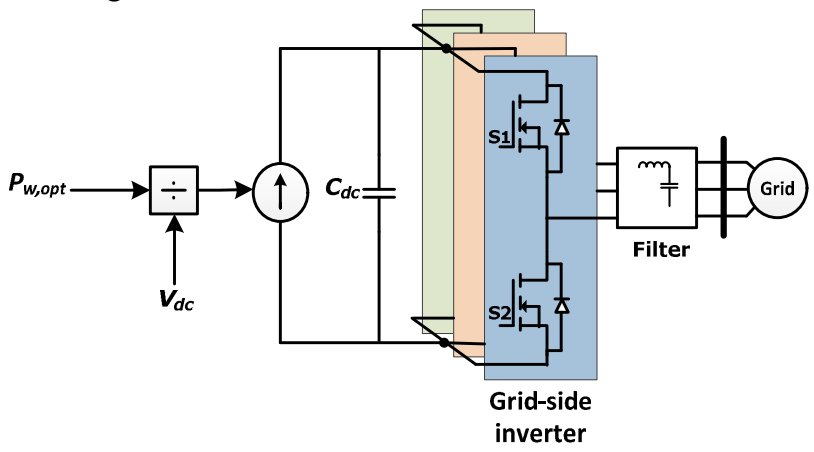

Fig. 2. Simplified model of small-scale wind turbine under MPPT.

In this work, the wind turbine maximum output power of a $10 \mathrm{~kW}$ commercial small-scale wind turbine shown in Fig. 3 is considered an input to the inverter stage, the minimum wind speed is $3 \mathrm{~m} / \mathrm{s}$ and the rated wind speed is $11 \mathrm{~m} / \mathrm{s}$.

\section{Wind Speed Distribution}

The wind speed distribution can be characterized by a Weibull distribution [10]:

$$
\varphi_{U}=(k / C)(U / C)^{k-1} \exp \left[-(U / C)^{k}\right] .
$$

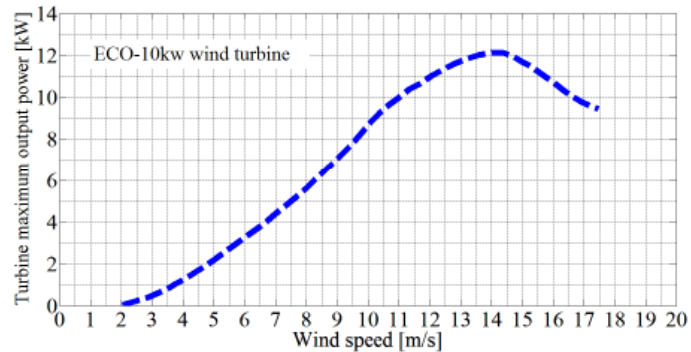

Fig. 3. ECO-10kW wind turbine maximum output power.

Where, $k$ [dimensionless] is the shape parameter and $C$ $[\mathrm{m} / \mathrm{s}]$ is the scale parameter. The scale parameter $C$ is related to the mean wind speed by the equation:

$$
C=2 U_{\text {mean }} / \sqrt{ } \pi \text {. }
$$

$U_{\text {mean }}[\mathrm{m} / \mathrm{s}]$ is the mean wind speed.

Fig. 4 shows the wind distribution in terms of hours per a year for a typical shape parameter $\mathrm{k}=2$, and a mean wind speed $U_{\text {mean }}=5.5 \mathrm{~m} / \mathrm{s}$. According to Fig. 4 , it is clear that the wind speed distribution is high at low wind speeds; on the other hand, the wind speed distribution is low at high wind speeds.

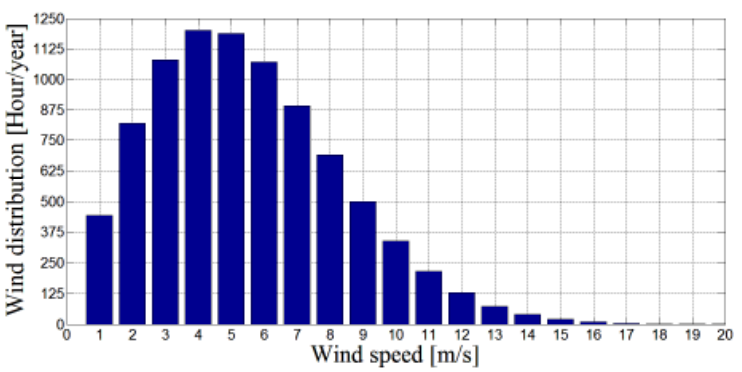

Fig. 4. Wind speed distribution.

The probability of the wind speed is the integration the Weibull distribution, and it is given as below [10]:

$$
\Phi(U)=\exp \left[-(U / C)^{k}\right] .
$$

By considering wind turbine parameters of ECO-10kW, and as shown in Fig. 5, the turbine with rated speed of $11 \mathrm{~m} / \mathrm{s}$ generates at full power only $4 \%$ of the time and at the minimum wind speed of $3 \mathrm{~m} / \mathrm{s}$; the turbine generates power about $80 \%$ of the time.

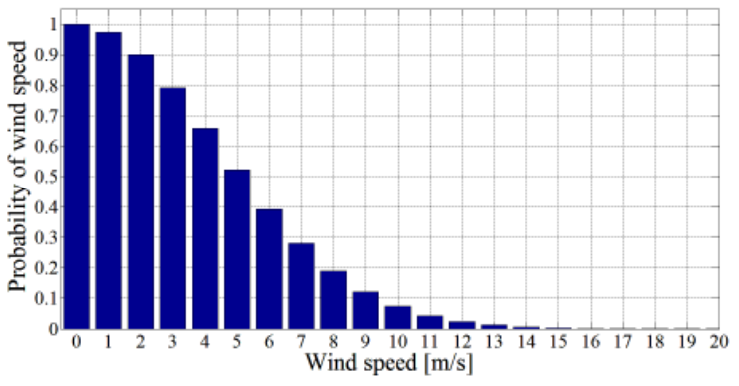

Fig. 5. Wind speed probability.

\section{TEMPERATURE SIC DEVICES CHARACTERISTICS}

The device characteristics refer to the device losses as a function of temperature and derived based on the curve fitting of manufacturer's data or test results for both static and 
dynamic characteristics. In this section, the important parameters required for calculating the conduction and switching losses for SiC MOSFETs and SiC Schottky diode are detailed.

The temperature dependency switching model of SiCMOSFETs at the converter test conditions of $V_{D C}=700 \mathrm{~V}$ and external gate drive $R_{g(e x t)}=10 \Omega$ is achieved experimentally by doing a double pulse test (DPT) for a 1200V/20A three phase power module (CCS020M12CM2 from CREE). The junction temperature of the device under test (DUT) is controlled by a hotplate. The double pulse test setup is shown in Fig. 6, the heatsink temperature is varied from $50^{\circ} \mathrm{C}$ to $90^{\circ} \mathrm{C}$, with an increment of $10^{\circ} \mathrm{C}$. Based on the results shown in Fig. 7, it is clear that the switching losses of SiC MOSFETs are almost constant with increasing the heatsink temperature and increases with increasing the current, so that, the switching losses can be represented by a polynomial of second order of current since it is in very good approximation temperature independent. This can lead to (5) that has been experimentally derived based on the curve fitting of the actual measurements of the switching losses as a function of drain current as shown in Fig. 8.

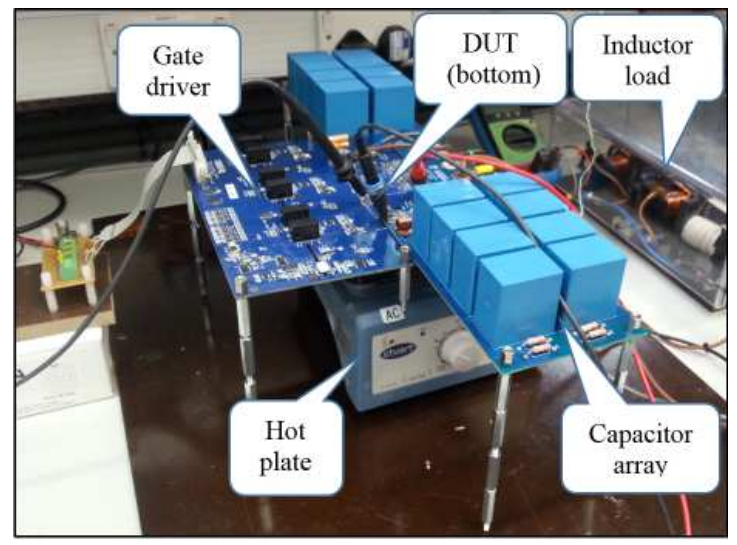

Fig. 6. . Double pulse test setup, the DC-link PCB is designed to minimize parasitic inductance based on 4 layers layout, and two sets of DC link is to have a asymmetric parasitic inductance between the individual half-bridge sections.

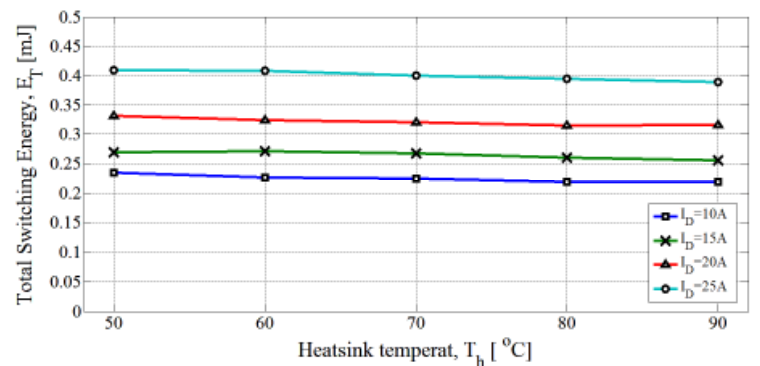

Fig. 7. Switching energy versus heatsink temperature at different current levels.

$$
E_{s w}=0.0003 i^{2}+0.0036 i+0.1726[\mathrm{~mJ}]
$$

SiC Schottky diode has approximately zero reverse recovery diode; therefore, its switching losses is neglected.

According to the manufacturer's datasheet, the on-state resistance of the SiC MOSFETs is nearly constant with respect to drain current and is a function of device junction temperature, thus, a second order approximation of on-state

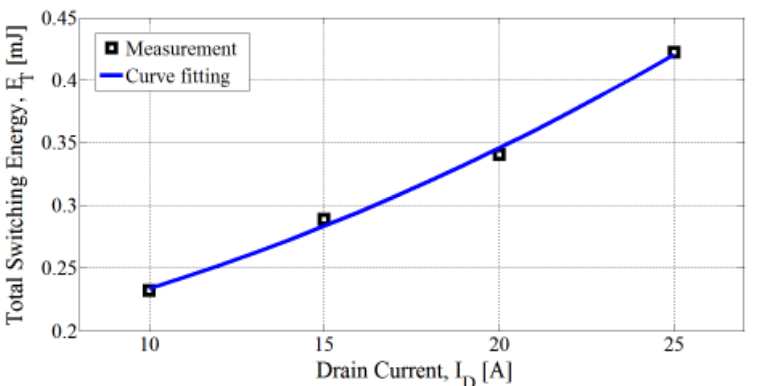

Fig. 8. Switching energy versus heatsink temperature at different current levels.

resistance as a function of junction temperature is needed in the losses calculation as given below [11].

$$
R_{S, \text { on }}=0.0019 T_{j}^{2}+0.1715 T_{j}+75.1845[\mathrm{~m} \Omega]
$$

The SiC Schottky diode temperature dependency can be modelled as a temperature dependant forward voltage $V_{D, o n}$ and forward resistor $R_{D \text {,on }}$ and their values at the given junction temperature can be calculated from the following equations [12].

$$
\begin{aligned}
& V_{D, \text { on }}=-1.4 \times 10^{-3} T_{j}+0.97 \\
& R_{D, \text { on }}=2.7 \times 10^{-4} T_{j}+0.023
\end{aligned}
$$

\section{THERMAL MODELING OF A CONVERTER SYSTEM}

The loss model is used to measure the total losses and junction temperature of a $12 \mathrm{~kW} 3$-phase inverter based on $1200 \mathrm{~V} / 20 \mathrm{~A}$ Cree SiC module. The total power loss of the wind turbine inverter Ploss,tot is calculated by summing the conduction and switching losses of SiC-MOSFETs and $\mathrm{SiC}$ Schottky diodes.

$$
P_{\text {loss }, t o t}=P_{S, c o n}+P_{D, c o n}+P_{S, s w}+P_{D, s w}
$$

The values of conduction losses for $\mathrm{SiC}$ MOSFET and Schottky diode are calculated as follows [13]:

$$
\begin{gathered}
P_{S, \text { con }}=I^{2}(1 / 8+(1 / 3 \pi) M \cos \varphi) \times R_{S, \text { on } .} \\
P_{D, \text { cond }}=I(1 / 2 \pi-(1 / 8) M \cos \varphi) \times V_{D, \text { on }}+ \\
I^{2}(1 / 8-(1 / 3 \pi) M \cos \varphi) \times R_{D, \text { on }}
\end{gathered}
$$

Where $M$ is the modulation index, $I$ [A] is the peak of output phase current, $\varphi[\mathrm{rad}]$ is the current phase shift.

The switching losses for $\mathrm{SiC}$ MOSFET switch is as follows [13]:

$$
P_{S, s w}=f_{s w}\left(\left(b_{2} / 4\right) I^{2}+\left(b_{1} / \pi\right) I+\left(b_{0} / 2\right)\right) \times 10^{-3}
$$

Where $b_{0}, b_{1}, b_{2}$ and $b_{3}$ are coefficients derived from MOSFET switching loss information from DPT results provided in the previous section.

The thermal circuit for devices in 2-Level FB converter is shown in Fig.9, where, $T_{j}$ is the junction temperature, $T_{c}$ is the case temperature, $R_{t h, j c}$ is the junction to case thermal resistance, $R_{t h, c h}$ is the case to heat sink thermal resistance.

The junction temperature for SiC-MOSFET devices and SiC Schottky diodes can be calculated by (13) and (14) respectively:

$$
\begin{aligned}
T_{j, S} & =P_{\text {loss }, S} R_{t h, j c, S} / 6+P_{\text {loss }, t o t} R_{t h, c h}+T_{h} \\
T_{j, D} & =P_{\text {loss }, D} R_{t h, j c, D} / 6+P_{\text {loss }, t o t} R_{t h, c h}+T_{h}
\end{aligned}
$$




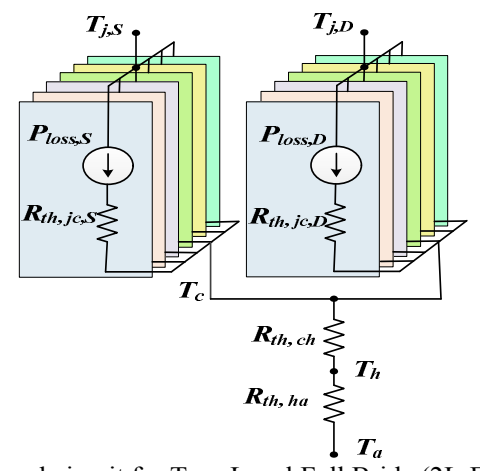

Fig. 9. Thermal circuit for Two-Level Full Bride (2L-FB) inverter.

Where, $P_{\text {loss }, S}$ is the loss of SiC-MOSFET device, $P_{l o s s, D}$ is the loss of SiC Schottky diode.

\section{HeAtsink Design AND Volume}

The heatsink thermal resistance can be calculated by the maximum power to be dissipated at a specific heatsink temperature as follow [14]:

$$
R_{t h, h a}=\left(T_{h}-T_{a}\right) / P_{\text {loss }}
$$

Where: $R_{t h, h a}$ is the heatsink thermal resistance $\left[\mathrm{W} /{ }^{\circ} \mathrm{C}\right], T_{h}$ is the reference heatsink temperature (equal to $60^{\circ} \mathrm{C}$ for some industrial applications), $T_{a}$ is the ambient temperature (chosen as $25^{\circ} \mathrm{C}$ ), and $P_{\text {loss, tot }}$ is the total semiconductor losses.

The heat sink volume and length based on natural and forced cooling is achieved by multiplying the heatsink's nominal thermal resistance $\left(R_{t h, n}\right)$ by the adjustable factor $(A F)$ which is based on the temperature difference between the heatsink and ambient temperature $(\Delta T)$ for the natural convection heatsinks and on the air speed via the heatsink fins (v) for the forced convection heatsinks $[15,16]$.

$$
\begin{gathered}
R_{t h, \text { adj }}=A F \times R_{t h, n} \\
A F_{n}=1.243 \times 10^{-4} \Delta T^{2}-2.143 \times 10^{-2} \Delta T+1.910 \\
A F_{f}=-2.163 \times 10^{-3} v^{5}+3.911 \times 10^{-2} v^{4}-2.767 v^{3}+ \\
9.912 \times 10^{-1} v^{2}-1.998 v+2.683
\end{gathered}
$$

The heatsink length can be calculated by [15]:

$$
L=\left(R_{t h, h a} / 37.715 R_{t h, a d j}\right)^{\wedge}(-1 / 0.725)
$$

\section{Reliabilty CALCULATION}

The failure rates and reliability models demonstrated in [17] are used to assess the reliability of the proposed thermal management. Although the reliability model was used for SiIGBTs in small scale wind turbine, some parameters are modified to be applied for the SiC-MOSFETs in the studied case in order to have more accurate results.

The life time $L\left(T_{j}\right)$ of a of the diode and the MOSFET is given as:

$$
L\left(T_{j}\right)=L_{0} \exp \left(B / \Delta T_{j}\right)
$$

Where $L_{0}$ is the device normal lifetime, CREE states that the life time of $1 \times 107$ hours can be achieved for the current $\mathrm{SiC}$ devices [18]; $B=\left(E_{a} / K_{B}\right), E_{a}$ is the activation energy which is equal to $0.06606 \mathrm{eV}$ [19], $K_{B}$ is Boltzman's constant; $\Delta T_{j}$ is the variation of semiconductor junction temperature and can be calculated as:

$$
1 / \Delta T_{j}=1 / T_{A}-1 / T_{j}
$$

The failure rate is described by:

$$
\lambda=1 / L\left(T_{j}\right)
$$

The global failure of grid connected inverter is calculated by:

$$
\lambda_{g r i}=6 \times\left(\lambda_{g r_{-} d}+\lambda_{g r_{-} \text {MOSFET }}\right)
$$

The inverter reliability is given by:

$$
R_{g r i}=\exp \left(-\lambda_{\text {grit }} t\right)
$$

\section{THERMAL MANAGEMENT OPTIMIZATION}

\section{A. Basic Idea}

The idea is illustrated on the basis of Fig. 10. Still the traditional heatsink design has to refer the maximum rated power $(12 \mathrm{~kW}$ in this application) in region III which actually shows lower wind speed distribution, the heatsink was designed to give a steady-state temperature of $60^{\circ} \mathrm{C}$ (a reference value for some industrial applications, i.e. $\mathrm{PV}$ and wind turbines). Alternatively, designing for a maximum full load temperature of $100^{\circ} \mathrm{C}$ corresponds to $60^{\circ} \mathrm{C}$ heat-sink temperature at $7.7 \mathrm{~kW}$ in region II (the area of interest), which, although not the most probable working condition, is, however a more highly probable working condition. This corresponds to an estimated reduction heatsink size added to the decrease in the size of passive filter elements as a result of increasing the switching frequency, opening a new approach for increased system level power density.

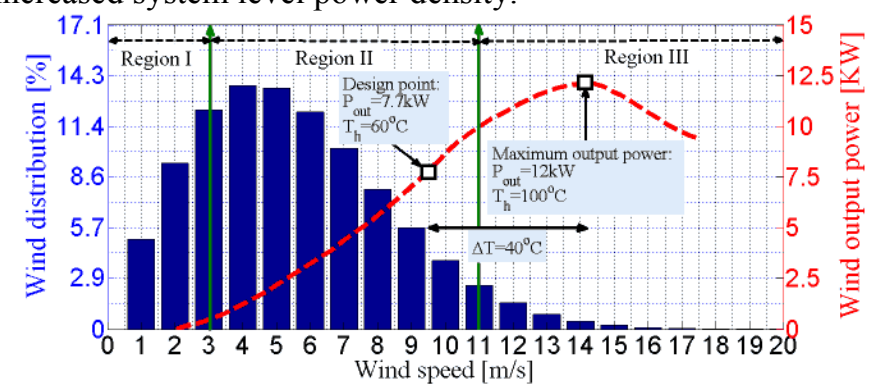

Fig. 10. Wind speed distribution and maximum output power vs. wind speed.

To achieve lower output power for heatsink design (higher wind speed distribution), the junction temperature must be increased accordingly in case of a given heatsink. The heat sink temperature also rises over the temperature range up to $225^{\circ} \mathrm{C}$ as shown in Fig. 11, which significantly improves the convective heat transfer and allows smaller heatsink volume. However, it is too high for present commercial packages. The accordingly higher heat sink temperature of $225^{\circ} \mathrm{C}$ is not possible to decrease the output power for heatsink design any more due to the falling heatsink thermal resistance, and, thus increasing the heatsink volume. This paper highlights the theoretical limit of the cooling system power density for this topology at this power level. 


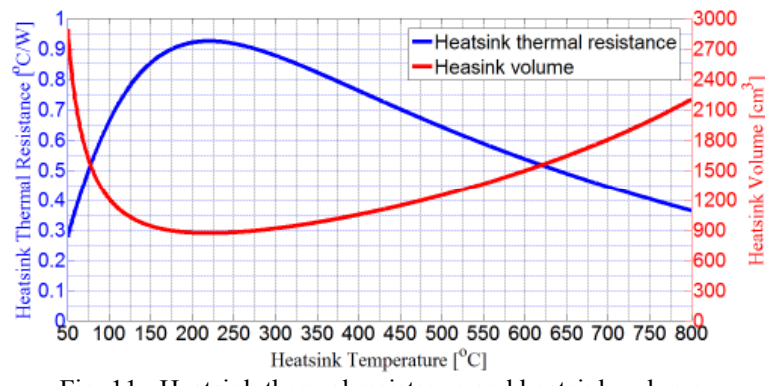

Fig. 11. Heatsink thermal resistance and heatsink volume vs heatsink temperature.

\section{B. The Resulting Thermal Management, Efficiency, Power Density and Reliability}

As illustrated in the previous sections, for different heatsink temperatures and different switching frequencies, the device junction temperature, furthermore, cell power losses, efficiency, heatsink volume, failure rates, and reliability can be calculated, and presented graphically for a detailed discussion.

To validate the temperature independency in the efficiency of 3-phase $12 \mathrm{~kW}$ converter based on six-pack $1200 \mathrm{~V} / 20 \mathrm{~A}$ power module, the heatsink temperature is varied from $60^{\circ} \mathrm{C}$ to $100^{\circ} \mathrm{C}$ at different switching frequency over a range of $16 \mathrm{kHz}, 32 \mathrm{kHz}$ and $48 \mathrm{kHz}$. According to the results in Fig. 12, the converter efficiency is almost independent of heatsink temperature and, thus junction temperature for the SiC MOSFETs and $\mathrm{SiC}$ Schottky diodes, and nearly stable over a wide range of switching frequencies.

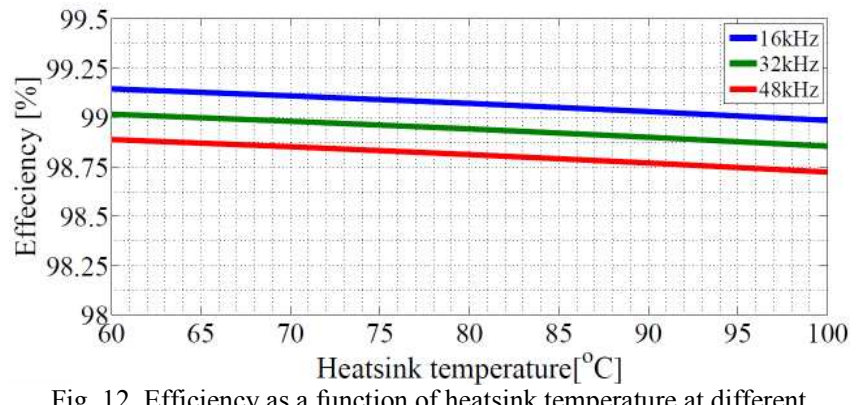

Fig. 12. Efficiency as a function of heatsink temperature at different switching frequencies at the maximum output power of $12 \mathrm{~kW}$.

Independence of efficiency from heat sink temperature gives an opportunity to optimize the design of the heat sink for wind turbine applications. As shown in Fig. 13, a reduction in heatsink volume of about $70 \%$ over a wide range of switching frequencies is achieved.

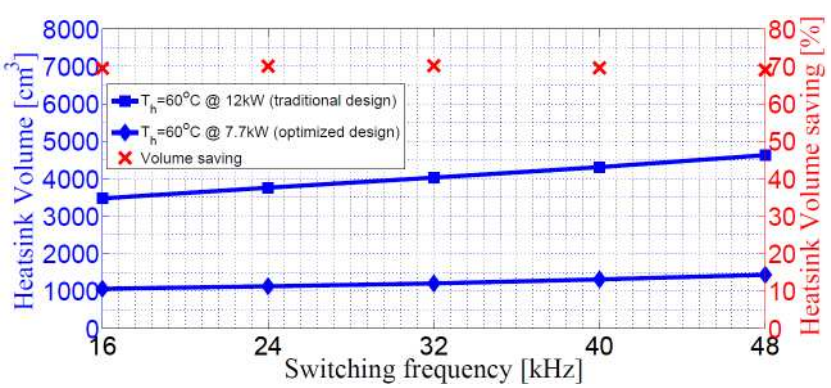

Fig. 13 Heatsink volume and volume saving vs. switching frequency for traditional and optimized heatsink design.
However, according to results shown in Fig. 12, moving from $60^{\circ} \mathrm{C}$ to $100^{\circ} \mathrm{C}$ heatsink temperature at the maximum output power of $12 \mathrm{~kW}$ and $48 \mathrm{kHz}$ switching frequency causing in the worst case a drop in efficiency about $0.16 \%$. In more details, Fig 14 shows the power loss increase by adopting the optimized heatsink design, and particularly in the area of higher wind speeds, resulting in the worst case in $17 \mathrm{~W}$ at the maximum output power. Fortunately, as shown in Fig. 4, the wind speed distribution around the area of high wind speeds is low which means lower operational time during one year, and thus lower lost energy and money, causing just $8.3 \mathrm{kWh}$ lost energy and $0.71 £$ lost money based on the existing UK infeed tariff for small-scale wind turbines $(8.54 \mathrm{p} / \mathrm{kWh})$.

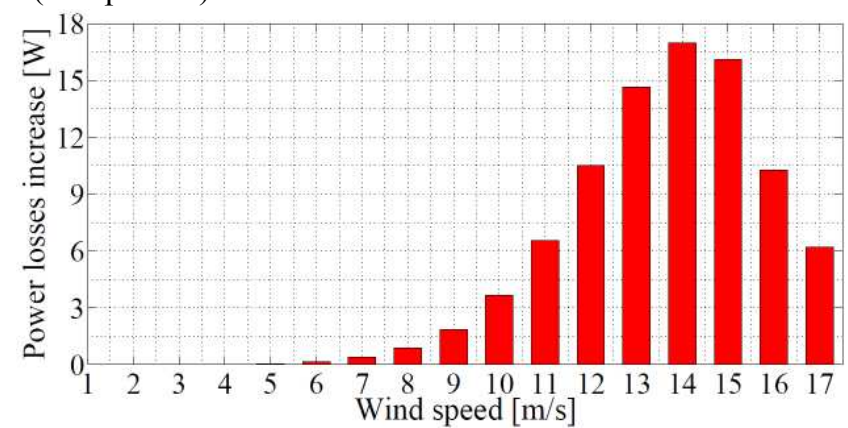

Fig. 14. The power loss increase for the optimized heatsink design vs. different wind speeds at the maximum output power of $12 \mathrm{~kW}$ and switching frequency of $48 \mathrm{kHz}$.

Fig. 15 demonstrates the inverter system failure rates by considering the traditional and optimized heatsink design. Incorporating the probabilities of wind speeds as presented in Fig. 5 results in insignificant failure rate differences for the traditional and optimized heatsink design over the whole operation range of wind speeds.

Fig. 16 shows the inverter system reliability incorporated the wind speed probabilities for the wind turbine working at the rated wind speed of $11 \mathrm{~m} / \mathrm{s}$ for a period of 10 years. The results reveals that the reliability of the inverter for the optimized heatsink design drops to $88.1 \%$ after ten years, while the reliability of the inverter system for the traditional heatsink design drops to $89.3 \%$ after ten years. It is well understood that optimized heatsink thermal design exhibits inverter system reliability close to the reliability for the traditional heatsink design.

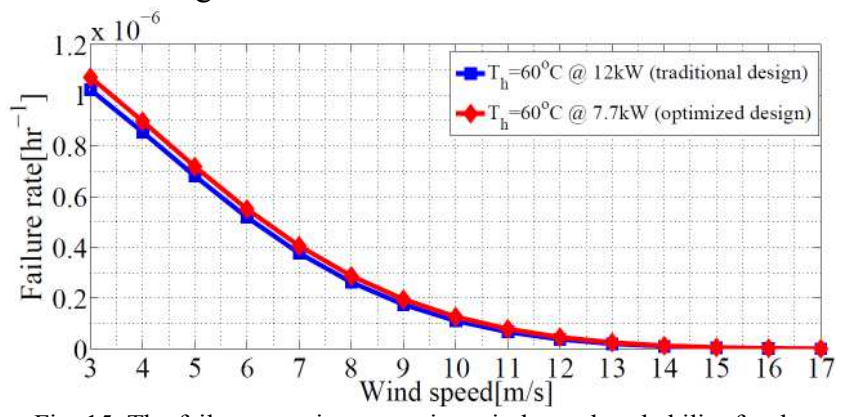

Fig. 15. The failure rates incorporating wind speed probability for the optimized and traditional heat sink design vs. different wind speeds. 


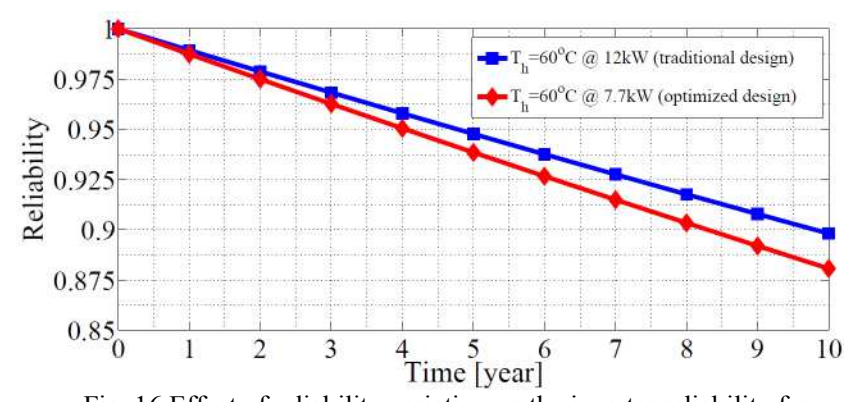

Fig. 16 Effect of reliability variation on the inverter reliability for traditional and optimized heatsink design.

\section{CONCLUSION}

Given the fact that SiC MOSFETs exhibit a very good stable operation over a wide range of heatsink temperatures. When this merit taken in to account in addition to the wind speed distribution over a year, the authors have proposed an approach to design the heatsink at nominal operational conditions, typically corresponding to lower than maximum power rating at a more highly probable wind speed distribution. This corresponds to an estimated reduction heatsink size of about $70 \%$, and opening up an approach to increase the converter power density. However, insignificant drop in efficiency, energy production and reliability are reported.

\section{REFERENCES}

[1] Castellazzi, A., et al., SiC power MOSFETs performance, robustness and technology maturity. Microelectronics Reliability, 2016. 58: p. 164-176.

[2] De, D., et al. An all SiC MOSFET high performance PV converter cell. in Power Electronics and Applications (EPE), 2013 15th European Conference on. 2013. IEEE.

[3] Gurpinar, E., et al. Performance analysis of SiC MOSFET based 3-level ANPC grid-connected inverter with novel modulation scheme. in 2014 IEEE 15th Workshop on Control and Modeling for Power Electronics (COMPEL). 2014.

[4] Wang, Z., et al. Impact of $\mathrm{SiC}$ technology in a three-port active bridge converter for energy storage integrated solid state transformer applications. in Wide Bandgap Power Devices and Applications (WiPDA), 2016 IEEE 4th Workshop on. 2016. IEEE.

[5] Togashi, R., et al. Performance improvement of ultra-high-speed PMSM drive system based on DTC by using SiC inverter. in 2014 International Power Electronics Conference (IPEC-Hiroshima 2014 ECCE ASIA). 2014.

[6] Blinov, A., et al. Feasibility study of $\mathrm{Si}$ and SiC MOSFETs in high-gain $\mathrm{DC} / \mathrm{DC}$ converter for renewable energy applications. in Industrial Electronics Society, IECON 2013-39th Annual Conference of the IEEE. 2013. IEEE.

[7] Hussein, A., et al. Performance benchmark of Si IGBTs vs. SiC MOSFETs in small-scale wind energy conversion systems. in Power Electronics and Motion Control Conference (PEMC), 2016 IEEE International. 2016. IEEE.

[8] Malinowski, M., et al., Optimized Energy-Conversion Systems for Small Wind Turbines: Renewable energy sources in modern distributed power generation systems. IEEE Power Electronics Magazine, 2015. 2(3): p. 16-30.

[9] Blaabjerg, F., M. Liserre, and K. Ma, Power electronics converters for wind turbine systems. Industry Applications, IEEE Transactions on, 2012. 48(2): p. 708-719.

[10] Caretto, L., Use of probability distribution functions for wind. Mechanical Engineering, 2010. 483.
[11] Silicon Carbide power MOSFET module, $1.2 \mathrm{kV}, 80 \mathrm{~m} \Omega$ Silicon Carbide Six-Pack (Three Phase) CREE CCS020M12CM2 data-sheet.

[12] Silicon Carbide Schottky Diode, 1.2kV, 26A CREE C4D20120A datasheet.

[13] Zhang, H. and L.M. Tolbert, Efficiency impact of silicon carbide power electronics for modern wind turbine full scale frequency converter. IEEE Transactions on Industrial Electronics, 2011. 58(1): p. 21-28.

[14] Seshasayee, N., Understanding thermal dissipation and design of a heatsink. Texas Instruments, Dallas, 2011.

[15] Laird, I., X. Yuan, and N. McNeill. A holistic approach to optimise the power density of a silicon carbide (SiC) MOSFET based three-phase inverter. in 2015 IEEE 11th International Conference on Power Electronics and Drive Systems. 2015. IEEE.

[16] 2002 Extrusion Selection Guide Power Profiles for the European Market, Aavid Thermalloy, 80 Commercial Street, Concord, New Hampshire, USA, 2002.

[17] Arifujjaman, M., M.T. Iqbal, and J.E. Quaicoe. A comparative study of the reliability of the power electronics in grid connected small wind turbine systems. in 2009 Canadian Conference on Electrical and Computer Engineering. 2009.

[18] A. Scott, "Silicon Carbide MOSFETs for High Powering Modules", APEC-tutorial, 2013.

[19] Sintamarean, N.C., et al., Reliability Oriented Design Tool For the New Generation of Grid Connected PV-Inverters. IEEE Transactions on Power Electronics, 2015. 30(5): p. 2635-2644. 